\title{
Numerical simulation of scale-model smoke contamination of upper atrium levels by a channelled balcony spill plume
}

\author{
Chee Leong Ho, Kai Yuan Li and Michael John Spearpoint
}

\begin{abstract}
Smoke contamination of balconies due to a channelled spill plume at a lower level in an atrium might occur during a fire and could affect occupant safety during an evacuation. Previous experimental work has investigated the extent of smoke contamination, and this work describes a numerical modelling comparison of the experiments using the Fire Dynamics Simulator (FDS) computational fluid dynamics programme. Temperature, severity and height of smoke contamination are selected as the key parameters for comparison. The predictions of severity and height of smoke contamination are generally similar to the experimental results using a 'most severe point assessment of smoke contamination' assessment method. Although predicted temperatures are slightly lower than experimental values, FDS temperature slice files can be used at the most severe smoke contaminated point using a $10{ }^{\circ} \mathrm{C}$ temperature rise. This $10{ }^{\circ} \mathrm{C}$ threshold matches the criterion proposed in the previous experimental research. On the basis of the comparisons for the height of smoke contamination, the simulation results generally match a previously proposed equation for the height of smoke contamination above a balcony spill plume.
\end{abstract}

KEY WORDS: smoke; balcony contamination; modelling; FDS; spill plume; atrium

\section{INTRODUCTION}

Smoke induced by fire is one of the major hazards to occupants when it accumulates and spreads in an atrium. The spread of smoke is determined by different plume patterns, and for a balcony spill plume scenario, it is possible that the smoke will curl into upper balconies above the fire level to present a hazard to the occupants. Cox [1] attributed the inward smoke curl to the Coanda effect because of a low pressure region caused by 'warm' air between the spill plume and the atrium structure.

To avoid the upper level smoke contamination hazard, fire engineers have the option to install fully covered smoke curtains onto the atrium balconies. However, smoke curtains are potentially a costly solution especially in high-rise buildings where many levels may need protection. Therefore, it is appropriate to consider the possibility of smoke contamination in upper balconies in fire engineering design to determine whether curtains are necessary. Most of the current guidance regarding atria smoke management systems has focused on the calculation of smoke mass flow for removing smoke from the buildings. Guidance directly relevant to the upper balcony contamination is given by Morgan et al. [2], which states that a balcony that has a breadth of less than $2 \mathrm{~m}$ would cause the rising plume to curl inwards toward the atrium structure. NFPA 92B [3] indirectly addresses the issue of upper level contamination by stating that to manage smoke spread to communicating spaces that connect to the atrium, it is possible to provide either a barrier to transform a communicating space into a separated space or an opposed airflow through the opening to prohibit smoke spread into the communicating spaces. 
There has been limited experimental research on determining the likelihood of smoke contamination on upper balcony levels due to a spill plume. Hansell et al. [4] conducted a set of one-tenth scale experiments for spill plume contamination that led to the guidance given by Morgan et al. [2]. The equivalent full-scale balcony breadths in Hansell's experiments were $1.25,2.5$ and $5.0 \mathrm{~m}$. It was found that the extent of smoke contamination above the balcony was dependent on the balcony breadth where a balcony being broader than $2 \mathrm{~m}$ is unlikely to become contaminated by smoke. For balconies narrower than $2 \mathrm{~m}$, Hansell et al. suggested that the extent of smoke contamination depends on the plume width. Law [5] developed an empirical expression for spill plume entrainment on the basis of a reanalysis of the work of Hansell et al. and suggested that for balcony breadth less than $2.5 \mathrm{~m}$, it would likely have smoke contamination.

Poreh et al. [6] experimentally investigated smoke adherence to upper level walls in an atrium. They found that as long as the Froude number is greater than 1, then the plume will not adhere to the wall immediately, whereas the plume would immediately adhere when the Froude number is less than 1. An adhered plume is much more likely to cause smoke contamination, and using a one-tenth scale experiment rig, Harrison and Spearpoint [7] found that the presence of downstand at the spill edge will increase the likelihood of smoke contamination because of the vertical rising plume from the opening. More recent work on upper balcony smoke contamination has been carried out experimentally by Tan et al. [8] using a modified version of Harrison's one-tenth scale rig. An empirical equation was developed by Tan et al. to predict the smoke contamination in atria. However, the experiments were limited by the number of storeys, the volume of the atrium and the breadth of the balconies.

In order to further investigate the issue of upper level contamination, a numerical method is presented in this paper where the FDS (Fire Dynamics Simulator, version 5.3.0) CFD model is applied to simulate the experiments. Although there have been previous relevant numerical studies on the spill plume such as the work by Tilley and Merci [9], Quintiere and Grove [10], Harrison and Spearpoint [11], Chow [12], Chow and Li [13], Kerber and Milke [14] and McCartney et al. [15], none of these have focused on smoke contamination in upper balconies, and hence, it is worthy to make further investigations. The purpose of this paper is to assess the capability of FDS to simulate the smoke contamination behaviour obtained from the experiments of Tan et al. as a first step to further numerical studies described by Ho [16].

\section{TAN ET AL. EXPERIMENTS}

Tan et al. [8] conducted a series of experiments in a one-tenth physical scale model (Figure 1) representing a six-storey atrium building to study balcony spill plume smoke contamination on higher balconies. The model scaling laws complied with the Froude modelling correlation where $\dot{Q} \propto L^{5 / 2}, \dot{m} \propto L^{5 / 2}, \dot{V} \propto L^{5 / 2}, u \propto L^{1 / 2}$ and $T \propto L^{0}$. The scaling laws do not apply to conductive and radiative heat transfer processes; therefore, convective heat transfer was assumed to be the predominant heat transfer mechanism in the atrium region of the experiments.

Because of practical considerations, only three balconies were assessed in the experiments. Tan et al. performed 50 experiments in which the balcony breadths, plume widths and fire sizes were systematically varied. The balcony breadths were $0.15,0.20,0.30$ and $0.50 \mathrm{~m}$. A solid 0.1-m high upstand was located at each balcony edge. The plume widths were $0.2,0.4$, 
0.6, 0.8 and $1.0 \mathrm{~m}$. Steady state fire sizes were 5,10 and $15 \mathrm{~kW}$ using industrial methylated spirits as the fuel. The fuel was supplied to a $0.25 \times 0.25 \times 0.015 \mathrm{~m}$ high steel tray from a fuel reservoir via a flow meter.

\section{SECTION VIEW}

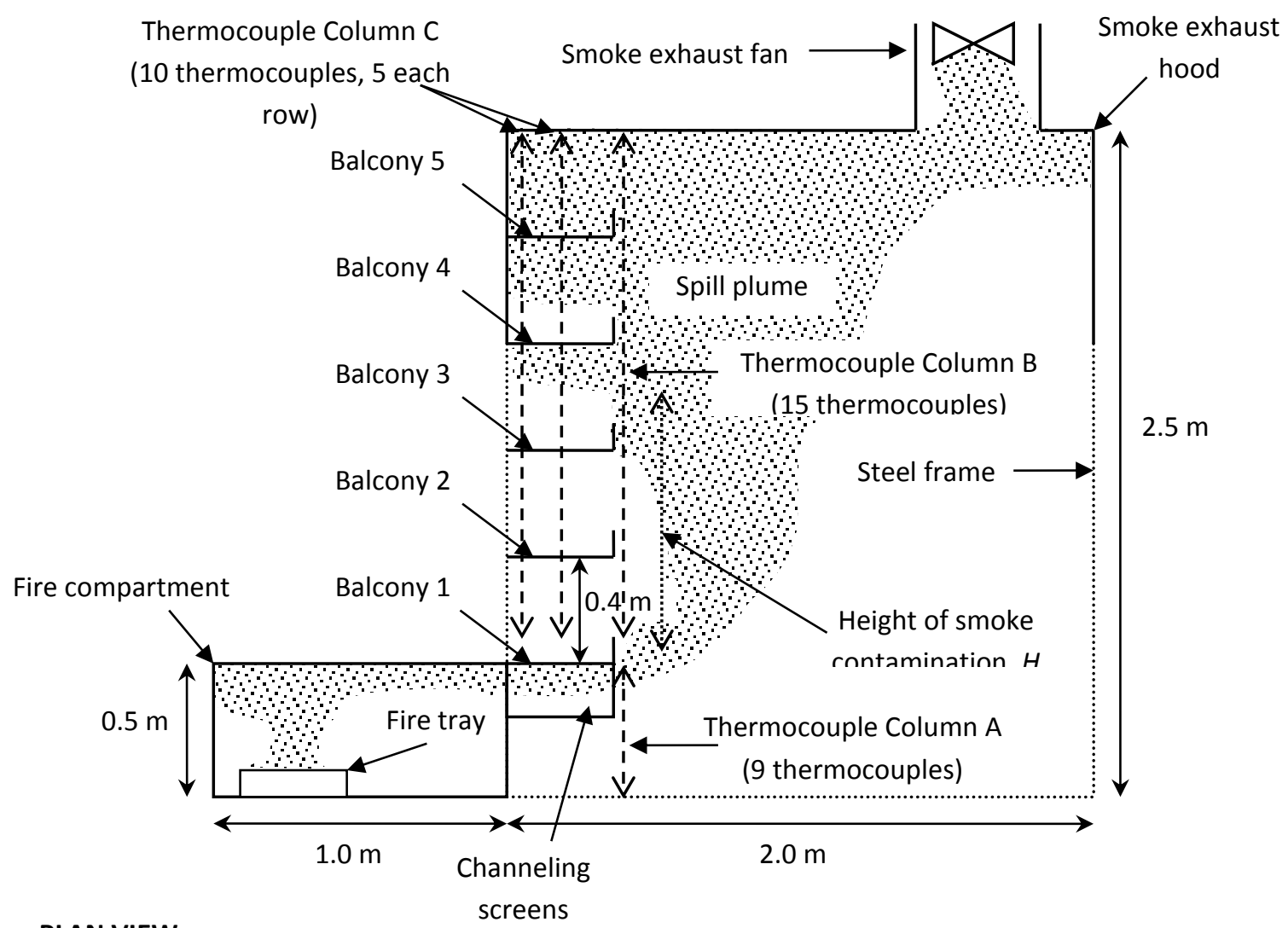

PLAN VIEW

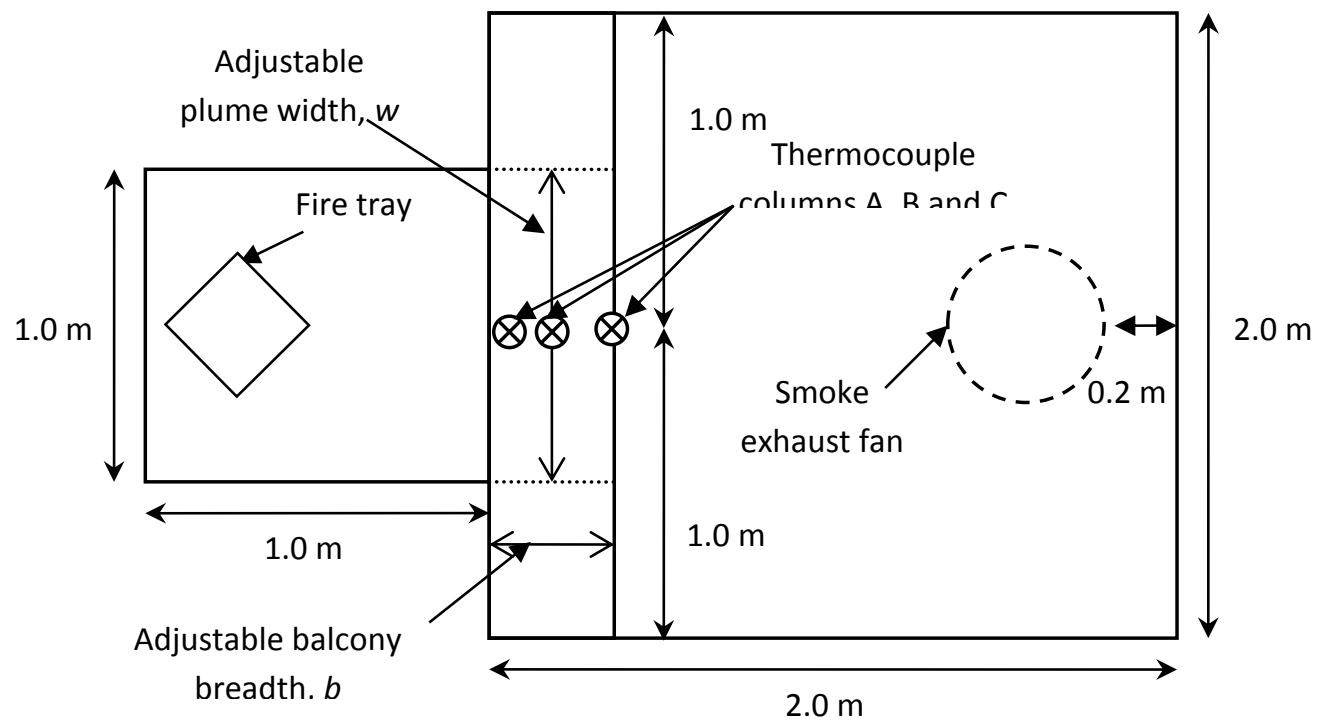

Figure 1. Schematic of Tan et al.'s experiment rig. 
A visual record of smoke flow was undertaken by injecting oil-mist smoke produced by a commercial smoke generator into the fire. Smoke was injected using three separate injection points spread laterally across the compartment width to ensure the smoke was distributed evenly. Thermocouples were used by Tan et al. to measure temperature profiles, which were used to match with the smoke observations. Three thermocouple columns, 'Column A', 'Column B' and 'Column C', were placed into the rig. Column A, with nine thermocouples, was located from the base of the atrium to the edge of Balcony 1 to measure the smoke temperature at the spill edge. Column B, with 15 thermocouples, was positioned away from the edge of Balcony 1 up to the atrium ceiling to identify the smoke contamination. The tips of the thermocouples were located at the nominal balcony edge within the realistic limits of accurately positioning the tips. Column $\mathrm{C}$ consisted of two rows aligning one thermocouple at the centre and one at the back of each balcony, respectively, as shown in Figure 1(a). More details of the experimental setup are not discussed here but can be found in Tan et al. [8].

\section{FDS MODEL}

\subsection{Physical model and material selection}

The dimensions of the numerical model fully match the experimental setup used by Tan et al. To clearly track the smoke flow (by using temperature profiles), the blockages in the model are specified to be transparent. Although the convective heat transfer is considered to be the predominant effect for the smoke flow pattern, the materials defined in the modelling are specified as similar as possible to the ones used in the experiments to minimise errors. The material types and properties used in the modelling are shown in Table 1.

Table 1. Key parameters selected for FDS modelling.

\begin{tabular}{|c|c|c|c|c|}
\hline Material & $\begin{array}{c}\text { Conductivity } \\
\left(\mathbf{W ~ m ~}^{-\mathbf{1}} \mathbf{K}^{\mathbf{- 1}}\right)\end{array}$ & $\begin{array}{c}\text { Density } \\
\left(\mathbf{k g ~ m}^{-\mathbf{3}}\right)\end{array}$ & $\begin{array}{c}\text { Specific heat } \\
\left(\mathbf{k J ~ k g}^{-\mathbf{1}} \mathbf{~ K}^{-\mathbf{1}}\right)\end{array}$ & $\begin{array}{c}\text { Thickness } \\
(\mathbf{m m})\end{array}$ \\
\hline CFI board & 0.041 & 229 & 0.82 & 16 \\
& {$[19]$} & {$[19]$} & {$[19]$} & \\
\hline Steel & 45.8 & 7850 & 0.46 & 1 \\
& {$[23]$} & {$[23]$} & {$[23]$} & 12 \\
\hline Acrylic & 0.19 & 1190 & 1.42 & \\
& {$[19]$} & {$[19]$} & {$[19]$} & \\
\hline
\end{tabular}

\subsection{Design fire and grid size}

The maximum steady-state heat release rate used in the experiments of Tan et al. was $15 \mathrm{~kW}$, and according to the scaling laws [8,17], this is equivalent to $4.8 \mathrm{MW}$ full-scale. This value is similar to some design codes [2,18] that stipulates that a 5-MW steady-state fire is appropriately conservative for sprinklered shop scenario. Tan et al. included fire sizes of 5 and $10 \mathrm{~kW}$ to represent smaller fire scenarios. For the FDS modelling, the fire source was specified as a burner with a given heat release rate per unit area, and the pool fire was located in the same position as the fire tray in the experiments. 
The gas phase reaction was specified as ethanol with heat of combustion of $26.8 \mathrm{MJ} / \mathrm{kg}$, and the radiative loss fraction for industrial methylated spirits is 20\% [19]. Grid size is an important parameter in FDS modelling. A $D^{*} / \mathrm{d} x$ criterion has been widely used for assessing the grid resolution [20], where $\mathrm{dx}$ is the grid size and the characteristic length of the fire $D^{*}$ is calculated by

$$
D^{*}=\left(\frac{\dot{Q}}{\rho_{\infty} c_{p} T_{\infty} \sqrt{g}}\right)^{\frac{2}{5}}
$$

It is recommended by McGrattan et al. [20] that the value of $D^{* / \mathrm{d} x}$ be in the range of 4 to 16 . Therefore, grid size of a finest mesh for a $5-\mathrm{kW}$ fire is calculated to be between 7 and $28 \mathrm{~mm}$. However, alternative grid assessment methods have been proposed by other researchers. Quintiere and Grove [10] suggest that the characteristic length of a line plume is determined by

$$
\begin{aligned}
z^{*} & =\left(\frac{\dot{Q}_{c} / w}{\rho_{\infty} c_{p} T_{\infty} \sqrt{g}}\right)^{2 / 3} \\
R & =\frac{\max (\delta x, \delta y, \delta z)}{z^{*}} .
\end{aligned}
$$

The dimensionless parameter $(R)$ is defined to assess the grid resolution requirement for fire plume simulations. It has been found by Quintiere and Ma [21] that the plume dynamics could only be accurately simulated if the resolution limit was about $R=0.1$ or smaller. Harrison et al. [22] also conducted a study of the 3D balcony spill plume using FDS modelling. A grid sensitivity study found that FDS generally provided a good prediction of the flow from the fire compartment and subsequent spill plume behaviour with grid size of $25 \mathrm{~mm}$ at one-tenth scale, equivalent to a grid size of $250 \mathrm{~mm}$ at full-scale. Harrison further elaborated that the chosen grid size must meet the criterion

$$
n_{s p i l l}^{*}=\frac{z^{*}}{\delta x} \geq 0.9
$$

for the grid size to be considered appropriate for spill plume. The experimental model characteristic length of Tan et al. is shown in Table 2, calculated using Equation (2). As shown in Table 2, using a 20-mm grid for the scale model meets the requirement of Equation (4) and McGrattan et al. [20]. Using a grid size of $25 \mathrm{~mm}$ as recommended by Harrison would not meet the criterion stated in Equation (4) for the most stringent case, and therefore, a uniform 20-mm grid size is selected for this study. The domain dimensions are $2.4 \times 2.2 \times 2.6 \mathrm{~m}$ for the atrium and $1.2 \times 0.9 \times 0.6 \mathrm{~m}$ for the fire compartment giving 1716000 grid cells in the atrium and 81000 grid cells in the fire compartment. 


\subsection{Smoke exhausting rate}

Unfortunately, Tan et al. did not record the smoke exhaust rate in the experiments because it was only necessary to provide sufficient extraction to ensure that smoke did not flow out of the bottom of the reservoir. However, for the FDS modelling, it is necessary to determine an appropriate extraction rate to ensure a meaningful comparison between the FDS modelling and the scaled experiment. To keep the smoke layer in the simulated hood from contaminating the lower balconies, a smoke exhausting fan was specified on the top of the smoke hood. For the scale model, the fan dimensions are taken to be $0.4 \times 0.4 \mathrm{~m}$ similar to that used in the experiments of Tan et al. Because the rig used in the work of Tan et al. was the same as that used by Harrison, it is appropriate to determine the smoke exhausting rate using Harrison's method [11] given as

$$
\dot{M}_{p, 3 D}=0.16 \dot{Q}_{c}^{1 / 3}\left(w^{2 / 3}+1.56 d^{2 / 3}\right) z+1.34 \dot{M}_{w}
$$

where $z$ must be not less than $z_{\text {trans }}$ calculated by

$$
z_{\text {trans }}=3.4\left(w^{2 / 3}+1.56 d^{2 / 3}\right)^{3 / 2}
$$

and

$$
d \approx \frac{1}{C_{d}}\left[\frac{M_{w}}{2 w}\right]^{2 / 3}
$$

Table 3 gives the calculated smoke extract rates used in the FDS modelling.

Table 2. Characteristic length and $n_{\text {spill }}^{*}$ with a 20-mm grid for FDS models.

\begin{tabular}{|c|c|c|c|}
\hline$\dot{Q}(\mathrm{~kW})$ & 5 & 10 & 15 \\
\hline$\dot{Q}_{c}(\mathrm{~kW})$ & 4 & 8 & 12 \\
\hline \multicolumn{4}{|c|}{ Width $=1 \mathrm{~m}$} \\
\hline$z^{*}(\mathrm{~m})$ & 0.02 & 0.04 & 0.05 \\
\hline$n_{\text {spill }}^{*}$ & 1 & 2 & 2.5 \\
\hline \multicolumn{4}{|c|}{ Width $=0.8 \mathrm{~m}$} \\
\hline$z^{*}(\mathrm{~m})$ & 0.03 & 0.04 & 0.06 \\
\hline$n_{\text {spill }}^{*}$ & 1.5 & 2 & 3 \\
\hline \multicolumn{4}{|c|}{ Width $=0.6 \mathrm{~m}$} \\
\hline$z^{*}(\mathrm{~m})$ & 0.03 & 0.05 & 0.07 \\
\hline$n_{\text {spill }}^{*}$ & 1.5 & 2.5 & 3.5 \\
\hline \multicolumn{4}{|c|}{ Width $=0.4 \mathrm{~m}$} \\
\hline$z^{*}(\mathrm{~m})$ & 0.04 & 0.07 & 0.09 \\
\hline$n_{\text {spill }}^{*}$ & 2 & 3.5 & 4.5 \\
\hline \multicolumn{4}{|c|}{ Width $=0.2 \mathrm{~m}$} \\
\hline$z^{*}(\mathrm{~m})$ & 0.07 & 0.11 & 0.14 \\
\hline$n_{\text {spill }}^{*}$ & 3.5 & 5.5 & 7 \\
\hline
\end{tabular}




\subsection{Selected experiment cases for FDS modelling}

Not all of the experiments conducted by Tan et al. have been modelled in FDS as it was found in the research by Tan et al. that all upper balconies would become contaminated when the aspect ratio $(w / b)$ is greater than 3.0, whereas no contamination occurred when the aspect ratio is less than 1.0. In terms of assessing the height of smoke contamination, around half of the 60 experiments had aspect ratios either greater than 3.0 or less than 1.0. Twelve representative cases have therefore been identified, as shown in Table 3, to ensure that a spread of aspect ratios $(\leq 3.0)$, plume widths and different heat release rates were modelled. The fully smoke free situation given by Experiment S13E with an aspect ratio of 0.4 was modelled so as to verify that FDS does not over-predict smoke contamination in such a case. Experiments with aspect ratios greater than 3.0, where smoke contamination will definitely occur in all balconies, are not simulated as such results could be extrapolated from other cases.

\section{RESULTS AND DISCUSSION}

\subsection{Temperature at the spill edge}

Harrison and Spearpoint [11] found that the spill plume behaviour and subsequent entrainment is dependent on the characteristics of the layer flow below the spill edge. Plumes from narrow openings with deep layers entrain air at higher rate with respect to height compared with plumes from wide and shallow layers. As the smoke flow at the spill edge strongly affects the plume, it is important to assure that the modelling gives a reasonable prediction at the spill edge before proceeding with an investigation of the contamination heights. There are experimental errors associated with the measurement of the fuel flow rate, the heat of combustion and hence the total heat release rate along with uncertainty in the radiative fraction. In this work, the smoke flow characteristics under the balcony could have been defined as a source term to reduce uncertainty; however, previous modelling smoke at the spill edge by Harrison et al. [22] shows that, with an appropriate grid selection, FDS is able to predict the smoke layer temperature and velocity profiles under the balcony within experimental error. A comparison between experiment measurements and FDS simulated temperature profiles for three typical cases with different aspect ratios and fire sizes is presented in Figure 2. The simulated results verify the acceptability of using a $20-\mathrm{mm}$ grid for simulation of the scale model. 


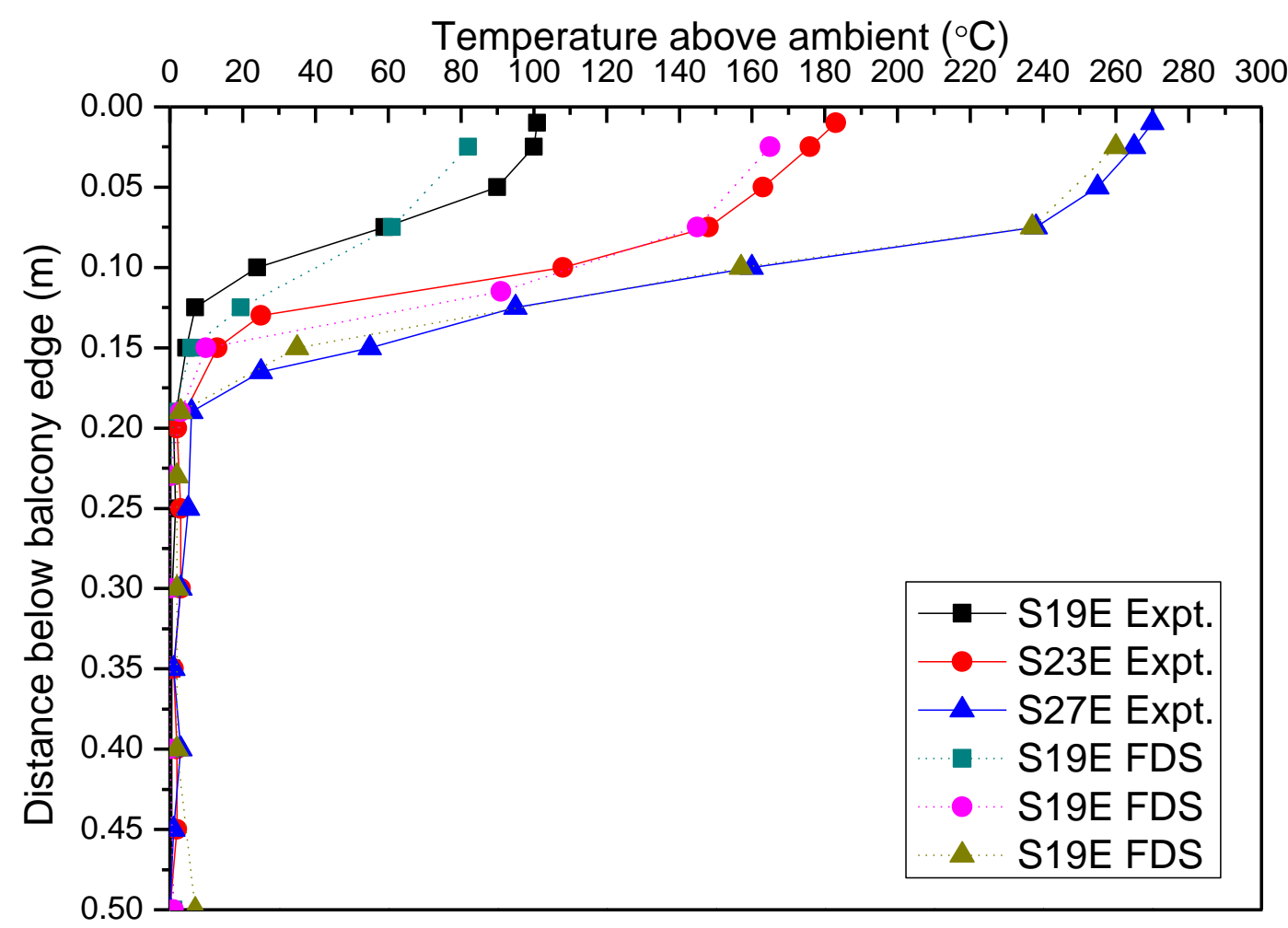

Figure 2. Comparison of measured and simulated smoke temperature profiles at the spill edge (where the dashed lines represent the experimental results).

\subsection{Comparison of simulations with experiments}

It took time for the smoke flow in the experiments to reach a steady-state condition where the average temperatures fluctuated by around $5 \mathrm{~K}$. At the start of an experiment, the spill plume would project away from the balconies and hit the compartment ceiling directly without attaching to the balconies.

Table 3. Selected experiments from Tan et al. for simulation.

\begin{tabular}{|c|c|c|c|c|c|}
\hline Simulation & $\begin{array}{c}\text { Balcony } \\
\text { breadth, } b \\
(\mathrm{~m})\end{array}$ & $\begin{array}{c}\text { Plume width, } \\
w(\mathrm{~m})\end{array}$ & $\begin{array}{c}\text { Aspect } \\
\text { ratio, } \\
w / b\end{array}$ & $\begin{array}{c}\text { Total heat } \\
\text { release rate, } \\
Q_{T}(\mathrm{~kW})\end{array}$ & $\begin{array}{c}\text { Exhausting rate } \\
\left(\mathrm{kg} \mathrm{s}^{-1}, \text { calculated }\right. \\
\text { from Eq. (5) to (7)) }\end{array}$ \\
\hline S01E & 0.50 & 1.0 & 2.0 & 5 & 0.44 \\
\hline S03E & 0.50 & 1.0 & 2.0 & 15 & 0.66 \\
\hline S08E & 0.50 & 0.6 & 1.2 & 10 & 0.48 \\
\hline S13E & 0.50 & 0.2 & 0.4 & 5 & 0.28 \\
\hline S19E & 0.30 & 0.8 & 2.7 & 5 & 0.40 \\
\hline S23E & 0.30 & 0.6 & 2.0 & 10 & 0.48 \\
\hline S27E & 0.30 & 0.4 & 1.3 & 15 & 0.50 \\
\hline S38E & 0.20 & 0.6 & 3.0 & 10 & 0.48 \\
\hline S41E & 0.20 & 0.4 & 2.0 & 10 & 0.43 \\
\hline S43E & 0.20 & 0.2 & 1.0 & 5 & 0.28 \\
\hline S56E & 0.15 & 0.4 & 2.7 & 10 & 0.43 \\
\hline S60E & 0.15 & 0.2 & 1.3 & 15 & 0.44 \\
\hline
\end{tabular}


In cases where balcony contamination occurred, the Coanda effect would then push the plume towards the balconies. Experimental measurements only recorded by Tan et al. after steady-state conditions were achieved.

It is found that the smoke flow and temperatures reach average steady-state conditions after around $100 \mathrm{~s}$ of simulation time where simulated temperatures fluctuate by $5 \mathrm{~K}$ similar to the experiments. The average and peak temperatures used for comparison are determined from the FDS results after $100 \mathrm{~s}$, and all of the analysis and conclusions have been drawn from these steady-state values. Comparison of temperatures along the balcony edge (Column B) shows that typically, the predicted temperatures (average values) are lower than those measured in the experiments. In two scenarios (cases S01E and S03E) out of the 12, the predicted temperatures are much lower than the experimental record, and the difference between the average temperature from FDS and experiment in some instances exceeds $20 \mathrm{~K}$, as shown in Figure 3. However, in terms of the overall results, the temperature at the top balcony, which is likely to be smoky, is generally closer to the experimental value compared with the other measuring locations. It can be seen in the simulations that the temperature measuring points inside the balconies are likely to be within the smoke layer once the smoke curls in and starts to fill the balcony, whereas those points along the edge are mainly dominated by the behaviour of the spill plume. As a result, the predictions inside the balcony are found to be better than at the edge when the balcony is smoke contaminated, as shown in Figure 4. Therefore, it is likely that the temperature differences at the balcony edge are partly caused by not being able to exactly locate the temperature measuring position in the simulation with that in the experimental setup where complex flow patterns may occur.

In terms of balcony contamination by smoke, it is the inside predictions that are more important rather than obtaining an exact match at the balcony edge. However in order to address this issue of not being able to closely match the thermocouple location, the highest temperature during the simulation is also compared with the experimental records. The experimental results are found to be typically bounded by the simulation average and simulation maximum (or peak) temperature other than in cases S01E and S03E. However, as shown in Figure 3, the highest temperatures are generally closer to the experimental records. The best prediction occurs in case S13E where the differences between the average and experimental temperatures are less than $5 \mathrm{~K}$, although the predictions are still lower than the experimental temperatures, as shown in Figure 3(d). It should be noted that TC-B1 gives a higher measured value than the FDS modelled temperature because of the direct attachment of smoke from the spill edge in the experiments. Figure 5 shows the simulation temperature profile (using an FDS slice file) at $25^{\circ} \mathrm{C}$ and $30^{\circ} \mathrm{C}$ with the photographic record of Tan et al. where it appears that FDS obtains a similar but not exactly the same trajectory as in the experiments. A slight variation in the FDS predictions of the smoke flow when compared with the position of TC-B1 will contribute to a marked divergence between simulation and experiment at that point.

With regard to the under-prediction of FDS, there are two issues needed to be taken into account. Firstly, FDS has been shown to under-predict the mass flow rate of spill plume in previous research [22], which is caused by less entrainment. Less entrainment will lead to less air in the plume, which will end up with a lower pressure difference for the Coanda effect that causes the smoke to curl in. Under-prediction of Coanda effect will keep the plume away from the balcony edge and eventually lead to an under-prediction of smoke contamination. However, the under-prediction could only account for around $10 \%$ as shown by Harrison, and in different plumes, the effect should be similar, which then makes it difficult to explain the 
difference between cases S01E and S03E. Apart from the under-prediction in entrainment, further investigation shows that the balcony upstand has a strong influence on the Coanda effect as it more likely to cause smoke attachment similar to other vertical boundaries. When the upstand is removed from a simulation, the smoke contamination is reduced, as shown in Figure 3(b), where in case S03E removing the upstand leads to temperature decrease along the balcony edge. Therefore, it can be deduced that as the plume gets wider, the effect of upstand becomes more prominent because more smoke ends up flowing across the balcony edge. For cases S01E and S03E where the plume width of $1 \mathrm{~m}$ is nearly twice of the maximum of the other cases simulated in this work, the plume is likely to be a line plume where the upstand effect would be greatest. As a result, the effect of less entrainment from the balcony edge is expected to be enhanced compared with the other cases, which will further under-predict the Coanda effect. More experiments should be conducted with regard to the plume width and upstand effect. This is likely to challenge the current version of FDS because it has been noted elsewhere by Harrison that the model does not do so well at predicting adhered plumes most likely because of the 'wall slip' algorithm, which is highly important in the upstand region.

Because smoke exhaust rates were not measured in the experiments, a sensitivity analysis is conducted on this aspect. Case S03E has been modified so that in one simulation, the hood fan is non-functioning and the other simulation has the hood ceiling removed. The results, as shown in Figure 6, demonstrate that the hood and the smoke exhausting process do not have a significant influence on the underside spill plume behaviour as long as the smoke layer is controlled above the hood. In the simulation where the fan is stopped, the smoke descends to the third balcony, which results in increasing temperatures in the balcony. However, the smoke layer does not strongly affect the rising plume. Where the hood ceiling has been removed, there is only a minor change in the temperature predictions throughout the whole plume. As a result, the smoke exhausting rate is not critical to the overall upper level contamination results.

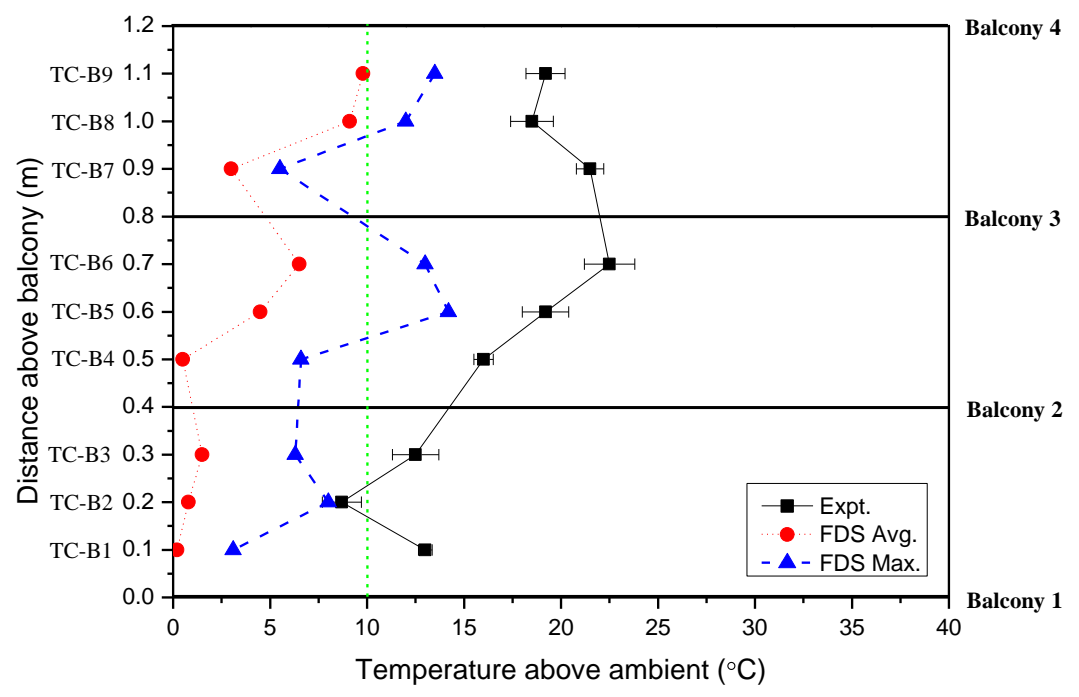

(a) S01E 


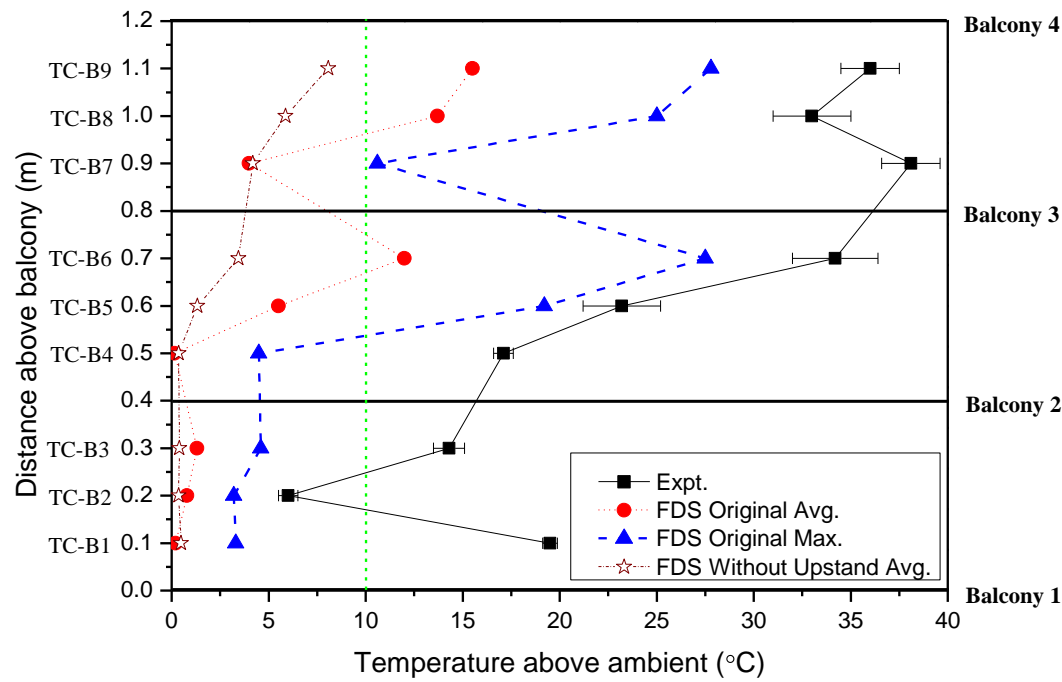

(b) S03E

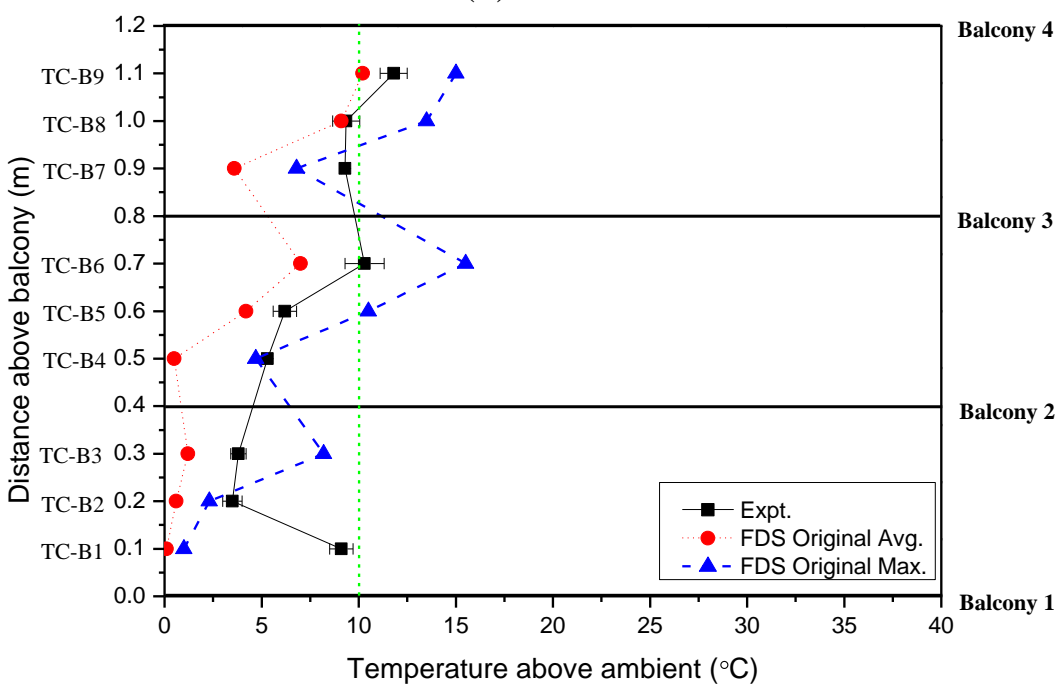

(c) S19E

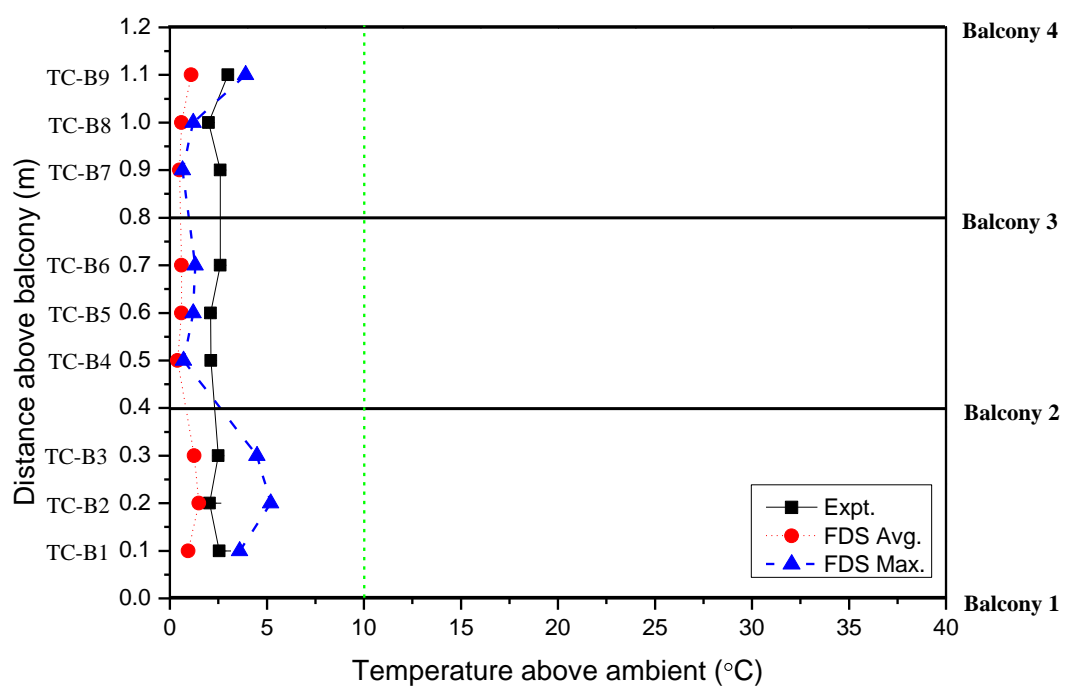

(d) S13E

Figure 3. Temperature along the balcony edge. 
Temperatures along the balcony breadth are also compared with generally closer results than those at the edge. As shown in Figure 4, two cases, S03E and S19E, are picked as being representative. The curves follow similar trends (similar to the temperature at the edge) where the temperature at the centre of the balcony is generally lower than the other two because of the smoke behaviour. The temperature in the middle of each balcony (along the edge) is used for the comparison in Figure 4.

Tan et al. [8] used a $10{ }^{\circ} \mathrm{C}$ above ambient condition (i.e. $30{ }^{\circ} \mathrm{C}$ ) as one criterion to assess whether smoke contamination had occurred, and this approach is investigated to evaluate the FDS simulations. The $10{ }^{\circ} \mathrm{C}$ criterion has also been indicated in Figures 3 and 4 with the horizontal or vertical dotted line as appropriate. It should be noted that in those cases with smoke contamination, FDS in general under-predicts the temperature and hence the contamination behaviour to some extent. Therefore, the simulated smoke actually contaminated the balcony less frequently than that in the corresponding experimental case. As a result, a 'most severe point' judgement was made for the comparison. In such cases, a balcony is determined to be smoke contaminated if smoke curls into the balcony at any time step during the simulation. The instant with the most severe smoke contamination (i.e. the most contaminated balconies with the lowest one being most seriously contaminated) is selected for the comparison. The method should be regarded as a fairly conservative practical assessment of smoke contamination in FDS. Figure 5 shows the comparison of the photographic records of Tan et al. and simulated temperature profiles. Ji et al. [24] observed that the fire induced ceiling jet flowing into open space with vertical side wall caused the boundary layer separation and investigated the phenomenon in detail. This phenomenon is also observed in our simulation. Figure 5 shows that it is reasonable to use the $30{ }^{\circ} \mathrm{C}$ temperature profile to determine the amount of smoke contamination in the balcony. Out of the 12 primary scenarios, only two simulations, S01E and S03E (Figure 5(a)), have a $25{ }^{\circ} \mathrm{C}$ temperature profile closer to the photographic records, although the $30{ }^{\circ} \mathrm{C}$ still gives acceptable results. Hence, the conclusion is drawn that a $30{ }^{\circ} \mathrm{C}$ profile (from an FDS slice file) in lieu of the temperature profiles across the balcony edge and along the balcony breadth can be used to determine the smoke contamination at the various levels. A summary of the assessment of smoke contamination from FDS compared with the experimental results of Tan et al. is shown in Table 4. The majority of the cases give a similar qualitative match compared with its corresponding experiment. Table 5 additionally presents the comparison of smoke contamination height between experiments and simulations. It is noted in Table 5 (as well as Table 4) that S56E is the exception out of 12 cases where FDS over-predicts the smoke contamination by a margin $0.68 \mathrm{~m}$ compared with around $0.11 \mathrm{~m}$ for the other cases, while the temperature predictions along the balcony edge show a maximum difference of less than $5 \mathrm{~K}$ higher than the experimental results. For the experiment itself, it is not unexpected that there is smoke contamination under such conditions for the given heat release rate and aspect ratio conditions. Other than that, FDS gives light contamination, whereas no contamination has been found in the experiment, such as S41E and S43E, because of the smoke flowing in a downward direction from the hood instead of the plume. These smallscale simulation results have shown that FDS can reasonably model the smoke contamination, although the predicted temperatures are usually lower, in line with Harrison's findings [22]. Hence, with the most severe point assessment of smoke contamination using FDS slice file for $30{ }^{\circ} \mathrm{C}$, the simulation could be extended to other balcony configurations. 


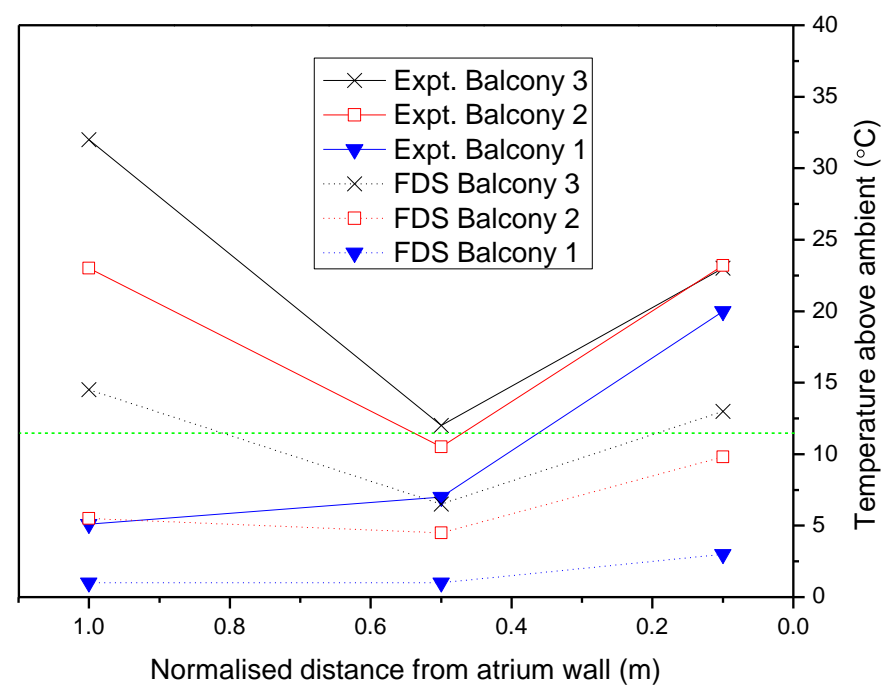

(a) Simulation S03E (0.50 m broad balcony)

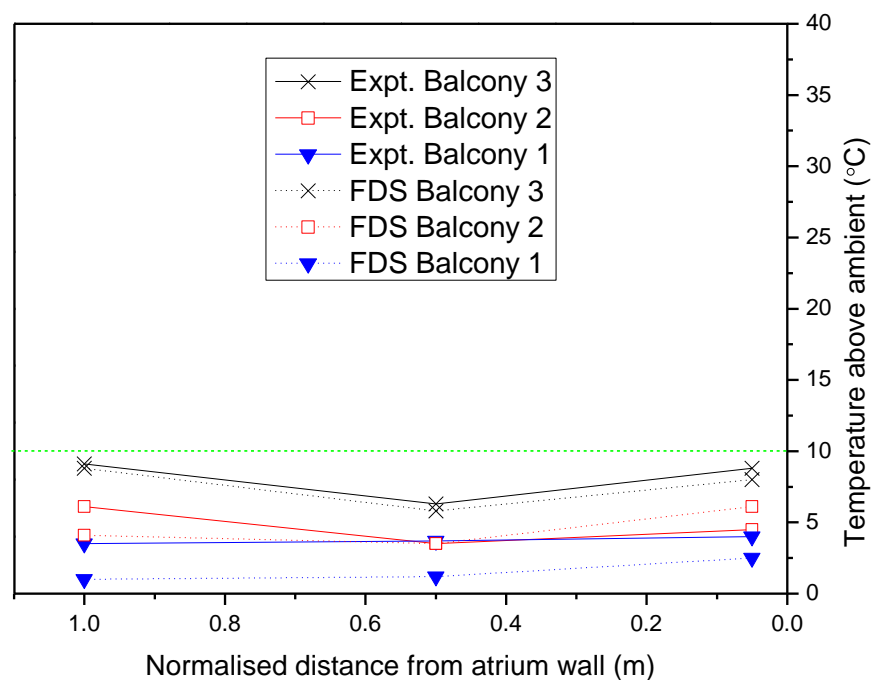

(b) Simulation S19E (0.30 m broad balcony)

Figure 4. Comparison of measured and simulated temperatures in the balcony. 


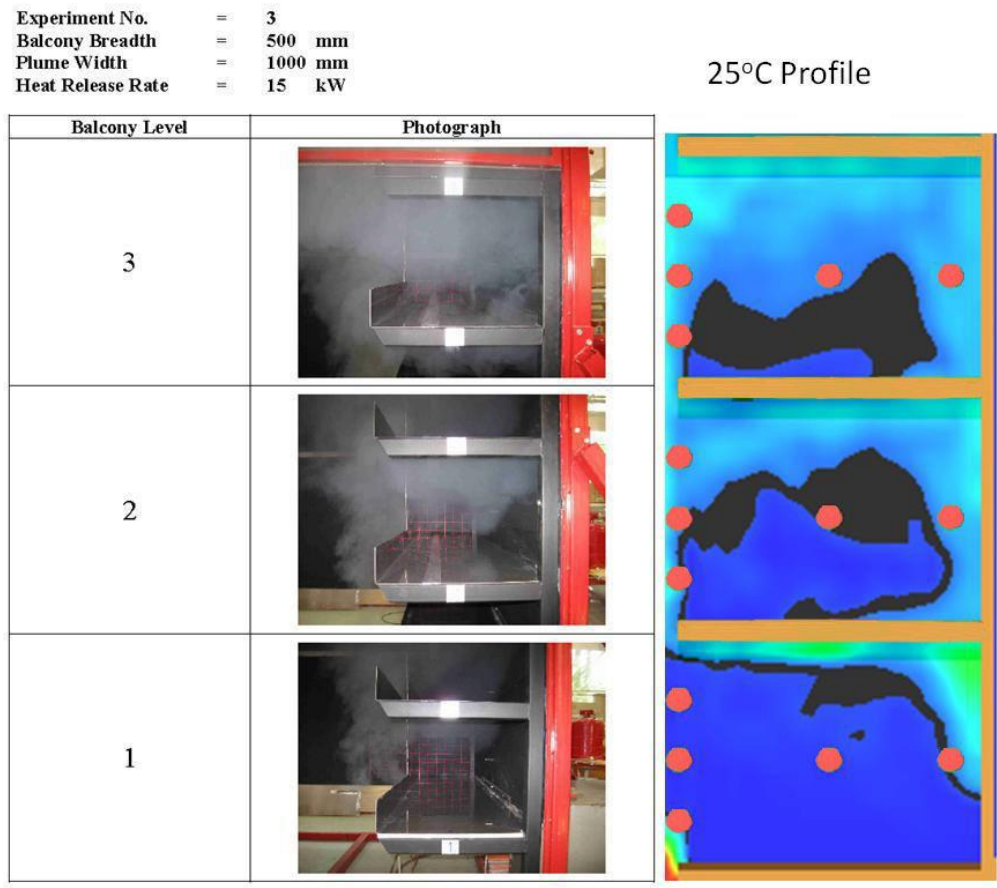

(a) Experiment 3 and simulation S03E

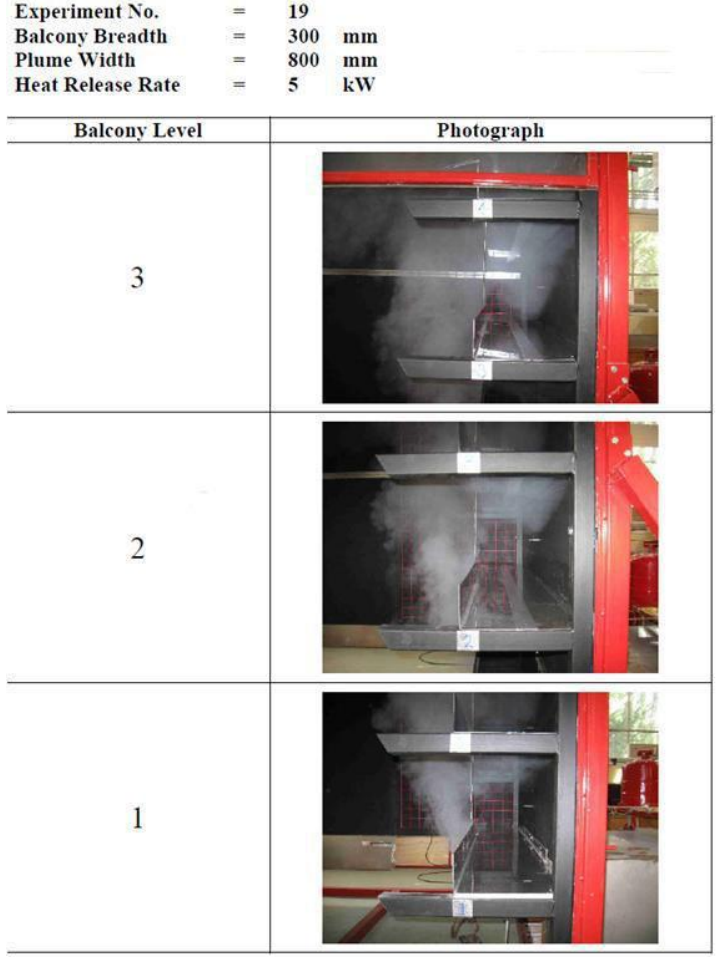

$25^{\circ} \mathrm{C}$ Profile

$30^{\circ} \mathrm{C}$ Profile
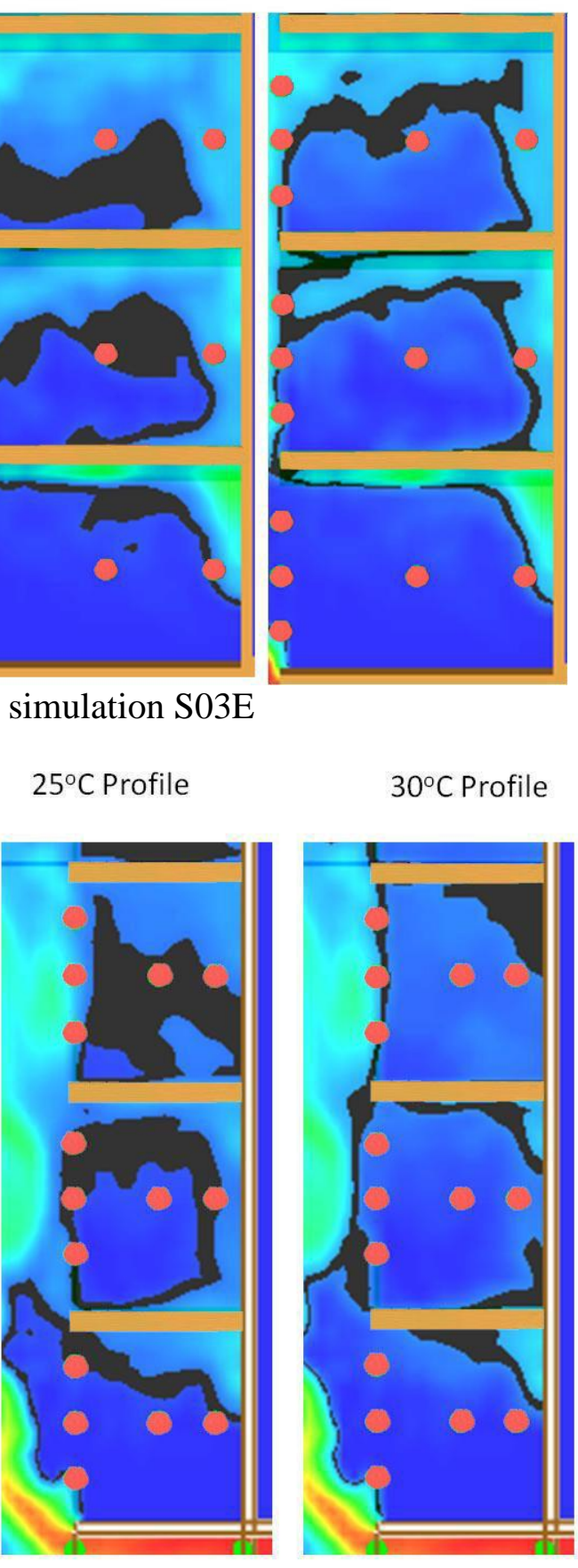

(b) Experiment 19 and simulation S19E

Figure 5. Comparison of the photographic records of Tan et al. and simulated temperature profiles. 


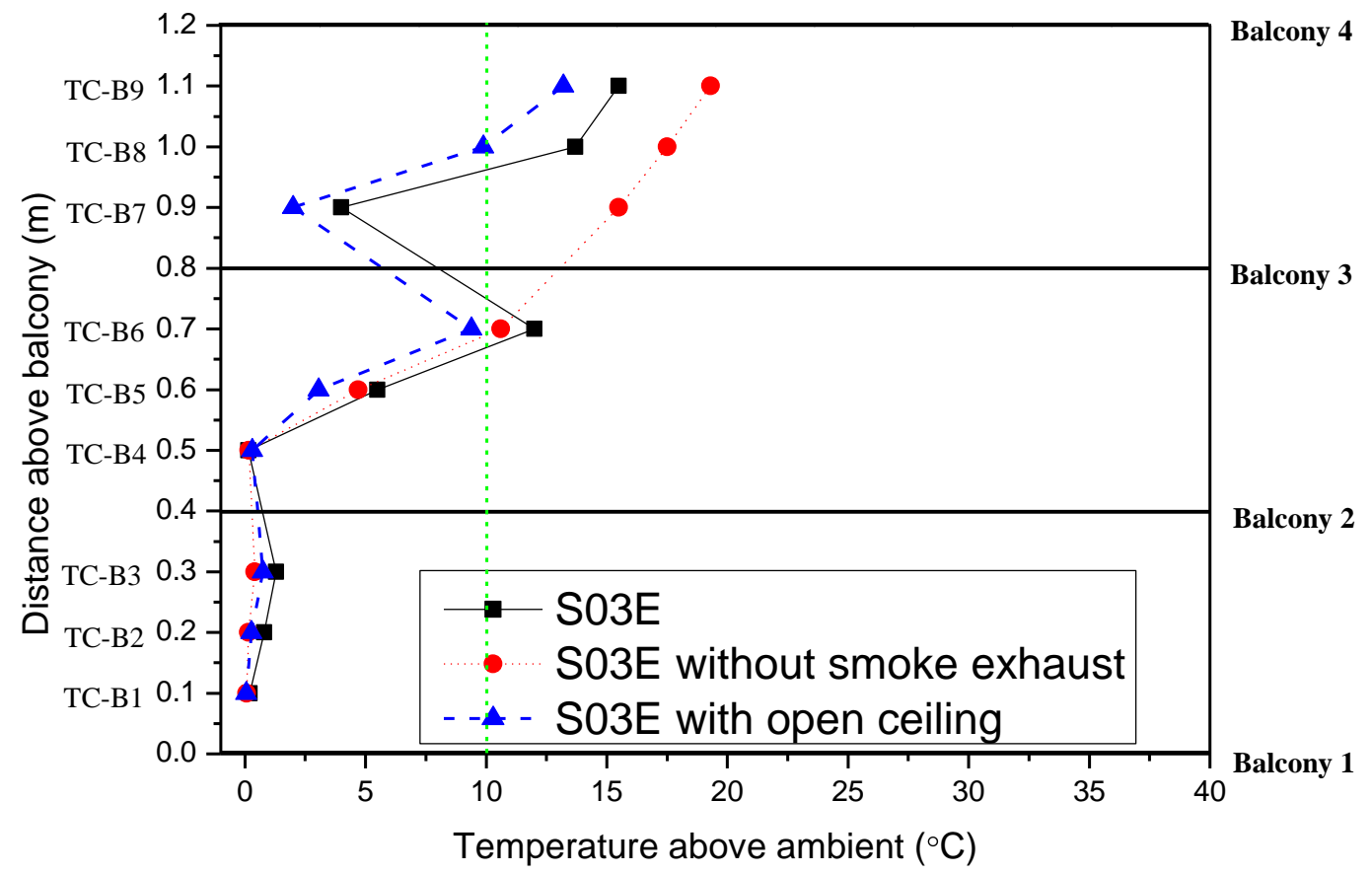

Figure 6. Temperature along the balconies for case S03E with no smoke exhaust and hood ceiling removed.

Table 4. Smoke contamination assessment from FDS and comparison with the experimental results of Tan et al.

\begin{tabular}{|c|c|c|c|}
\hline $\begin{array}{l}\text { Experiment or } \\
\text { simulation }\end{array}$ & Balcony 1 & Balcony 2 & Balcony 3 \\
\hline S01E & $\bullet / \square$ & O/ם & O/ם \\
\hline SO3E & $\bullet / \square$ & O/ロ & $\boldsymbol{O} / \mathbf{\square}$ \\
\hline S08E & $O / \square$ & $O / \square$ & $O / \square$ \\
\hline S13E & $O / \square$ & $O / \square$ & $O / \square$ \\
\hline S19E & $\bullet / \bullet$ & $\bullet / \bullet$ & $\boldsymbol{\theta / \square}$ \\
\hline S23E & $\mathrm{O} / \square$ & $\bullet / \bullet$ & $\boldsymbol{O} / \mathbf{\square}$ \\
\hline S27E & $O / \square$ & $O / \square$ & $O / \square$ \\
\hline S38E & $\bullet / \bullet$ & $\bullet / \bullet$ & O/ם \\
\hline S41E & $O / \square$ & $\bigcirc / \square$ & $\mathrm{O} / \square$ \\
\hline S43E & $O / \square$ & $O / \square$ & $O / \square$ \\
\hline S56E & $O / \square$ & $O / \square$ & $\bullet / \square$ \\
\hline \multirow[t]{2}{*}{ S60E } & $O / \square$ & $O / \square$ & $\bullet / \bullet$ \\
\hline & $\begin{array}{l}\text { Experimental } \\
\text { result }\end{array}$ & $\begin{array}{c}\text { Small-scale } \\
\text { three balcony } \\
\text { simulation }\end{array}$ & \\
\hline Clear & $\mathrm{O}$ & $\square$ & \\
\hline Shallow smoke layer & $\bullet$ & - & \\
\hline Deep smoke layer & 0 & $\mathbf{\square}$ & \\
\hline
\end{tabular}




\subsection{Sensitivity analysis of grid size}

In order to assess the effect of grid size, work was carried out to model the experiments of Tan et al. with a finer grid size. Because of computational resource limitations, only the region where the plume leaves the spill edge and travels along the atrium was modelled with a $10-\mathrm{mm}$ grid $(0.5 \times 0.5 \times 2.5 \mathrm{~m}$ as shown in Figure 7$)$, whereas the other regions retained a 20-mm grid as previously described. Such a configuration already reached the limit of a 32bit operating system so that it was not possible to apply this grid size to the whole computational domain.

Table 5. Comparison of smoke contamination height.

\begin{tabular}{|c|c|c|c|}
\hline Experiment & $\begin{array}{c}\text { Measured height of } \\
\text { smoke contamination, } H \\
(\mathrm{~m})\end{array}$ & $\begin{array}{c}\text { Simulated height of } \\
\text { smoke contamination, } H \\
(\mathrm{~m})\end{array}$ & $\begin{array}{c}\text { Difference } \\
\text { between } \\
\text { experiment and } \\
\text { simulation }(\mathrm{m})\end{array}$ \\
\hline S01E & 0.24 & 0.34 & 0.10 \\
\hline S03E & 0.25 & 0.35 & 0.10 \\
\hline S08E & $>1.20$ & 1.15 & - \\
\hline S13E & $>1.20$ & $>1.20$ & - \\
\hline S19E & 0.25 & 0.31 & 0.06 \\
\hline S23E & 0.70 & 0.70 & 0.00 \\
\hline S27E & $>1.20$ & 1.09 & - \\
\hline S38E & 0.25 & 0.36 & - \\
\hline S41E & $>1.20$ & 1.14 & - \\
\hline S43E & $>1.20$ & 1.12 & 0.68 \\
\hline S56E & 1.00 & 0.32 & 0.07 \\
\hline S60E & 1.10 & 1.03 & $0.11^{*}$ \\
\hline
\end{tabular}

- values not determined where heights of smoke contamination are stated as $>1.20 \mathrm{~m}$.

* excluding experiment S56E. 


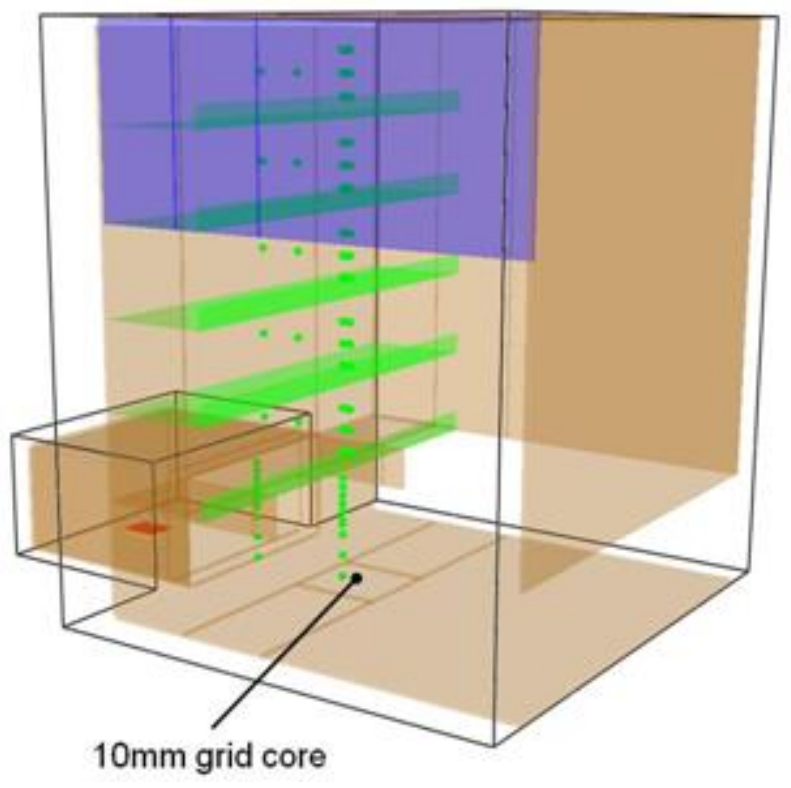

Figure 7. Model with inner 'core' 10-mm grid.

Figure 8 shows the comparison of three selected cases with a $20-\mathrm{mm}$ grid or a $10-\mathrm{mm}$ grid in the plume core. The general profile shapes of the average temperatures using either grid size are similar although in several cases, the temperatures from the finer grid are less than $5 \mathrm{~K}$ higher especially where the maximum average temperature is considered. Refining the grid size might improve the smoke behaviour prediction in case S19E where temperature of TC$\mathrm{B} 1$ is $4.5 \mathrm{~K}$ higher than that of TC-B2. However, in terms of the assessment of smoke contamination using the $10{ }^{\circ} \mathrm{C}$ above ambient criterion, the use of the finer grid does not appreciably change the outcome. Hence, a $20-\mathrm{mm}$ grid is adequate for the purposes of the present study. 


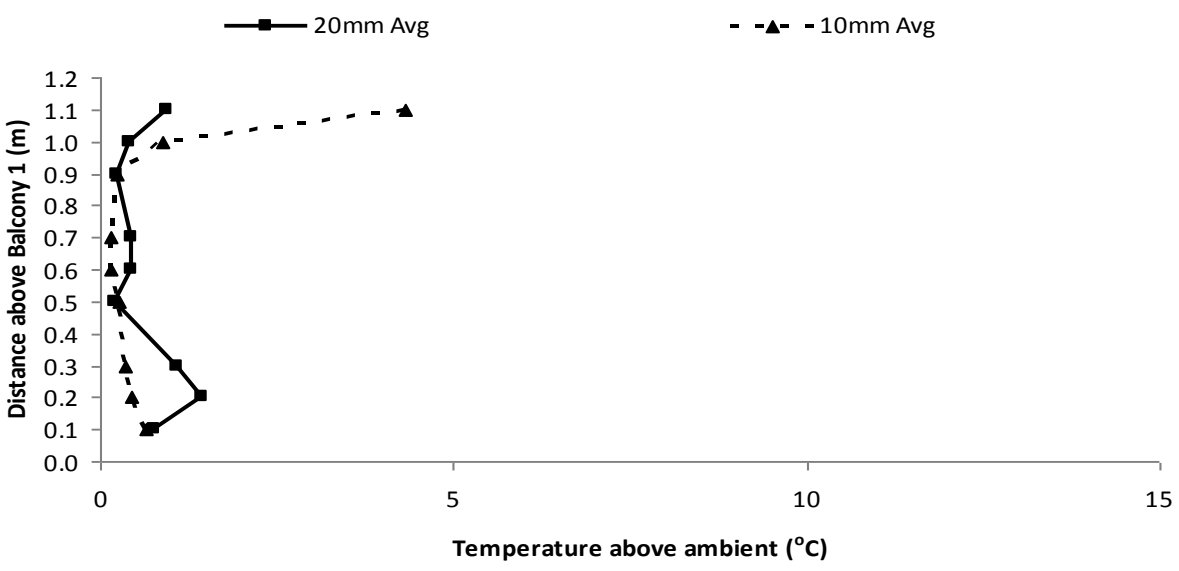

(a) Simulation S13E

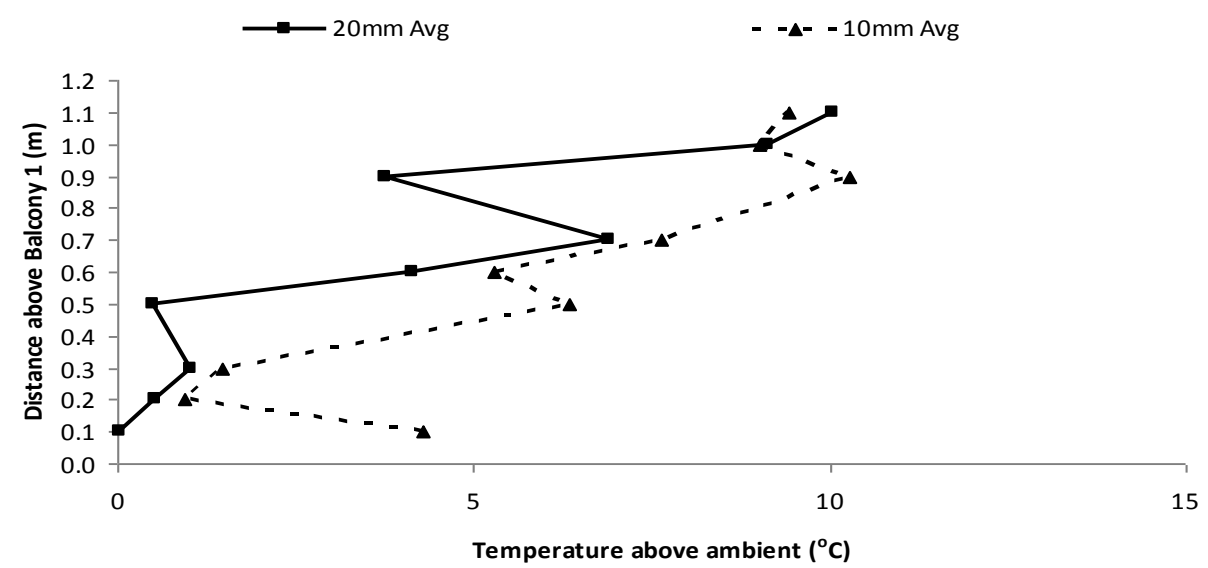

(b) Simulation S19E

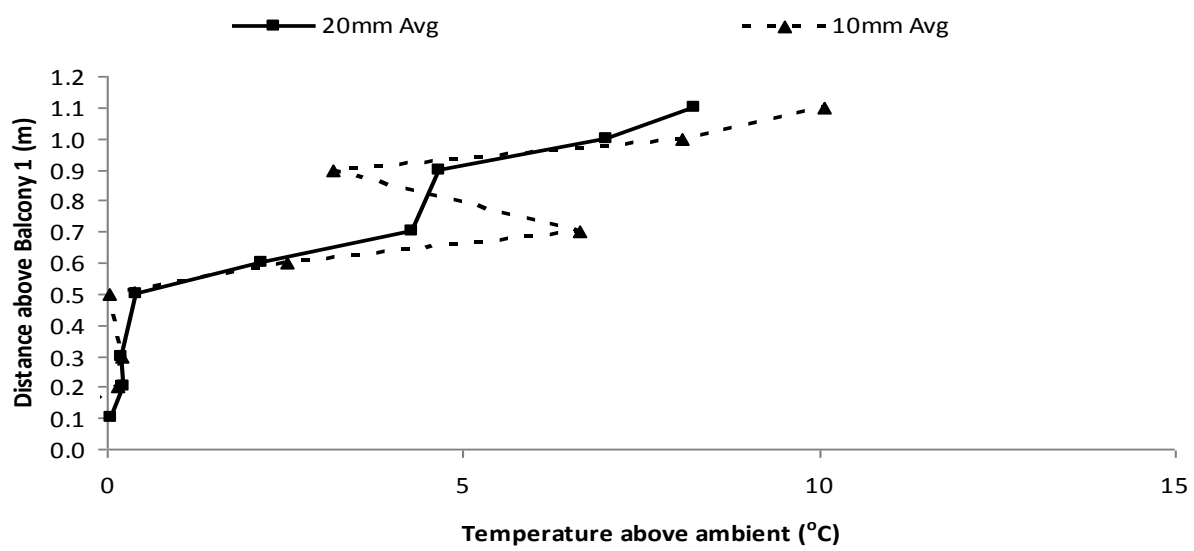

(c) Simulation S38E

Figure 8. Comparison of simulated plume core average temperatures using a 20 -mm grid and a 10 -mm grid. 


\subsection{Simulation results and experimental correlation}

Tan et al. [8] has proposed an empirical correlation to provide guidance on the extent of smoke contamination in upper balconies such that

$$
\frac{H}{b}=20\left(\frac{w}{d}\right)^{-1.5}
$$

Figure 9 shows the simulated results superimposed onto the experimental data from Tan et al. for the heights of smoke contamination. Both the simulation and experimental results are fitted by a power correlation where the two fitting curves are reasonably similar. The best fit given by the simulation results is

$$
\frac{H}{b}=10\left(\frac{w}{d}\right)^{-1}
$$

with a correlation coefficient of 0.86, as shown in Figure 9. The correlation coefficient increases from 0.81 to 0.83 once the experimental curve is fitted to the simulation data points, which indicates the simulated results from FDS also compares with the proposed correlation by Tan et al. However, as can be seen in Figure 9, the correlation of Tan et al. somewhat under-predicts the smoke contamination when $w / d$ is 1.2 or less leading to an $H / b$ value being around two times higher than the experimental result, whereas the new correlation gives improved results in such a case. There is not much difference between the two correlations when $w / d>3$, while it might be claimed that the correlation of Tan et al. performs better within the w/d range of 3 to 6 . It should be noted that the experimental result from S56E does not match with either correlations compared with its corresponding simulation value, although it did not affect the overall outcome.

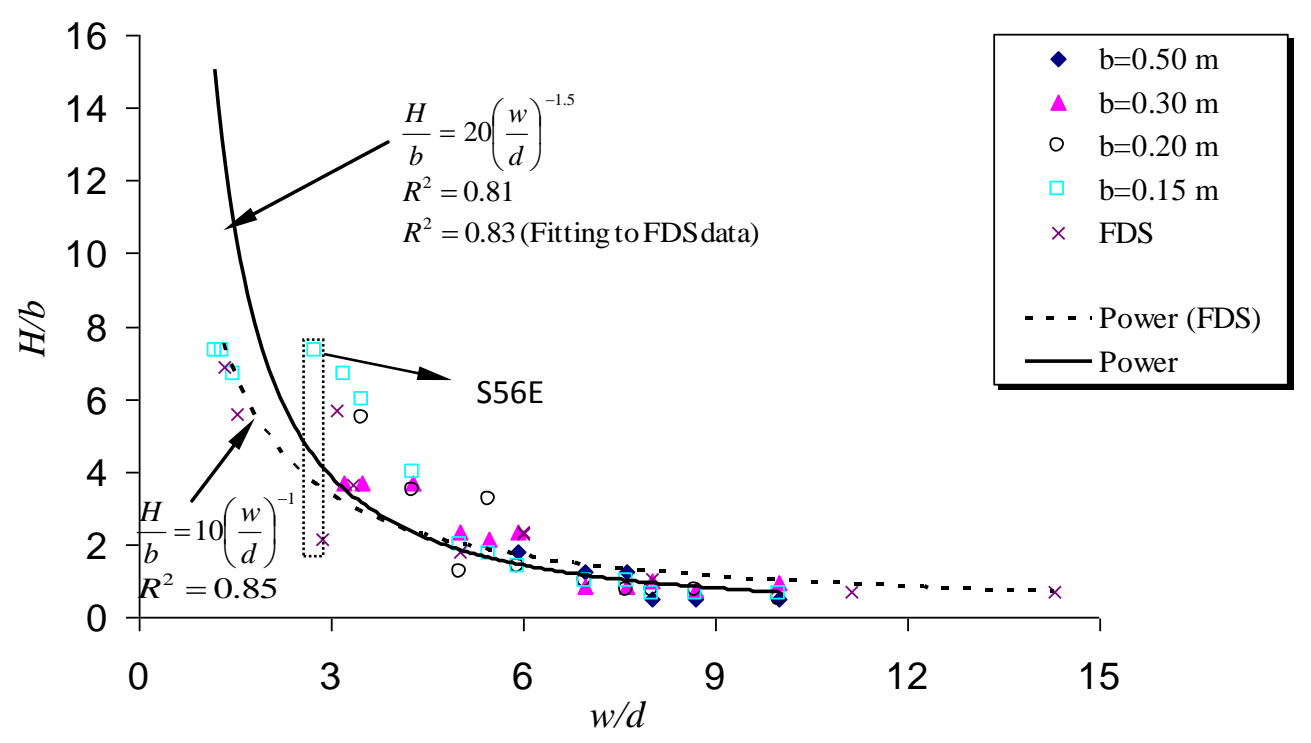

Figure 9. Comparison of smoke contamination heights derived from FDS small-scale simulations and experimental results. 


\section{CONCLUSIONS}

FDS generally is able to give similar predictions of the smoke contamination behaviour for balconies in an atrium due to a spill plume when compared with small-scale experiments conducted by Tan et al. By using the grid size recommended by Harrison and the assessment methodology of using the FDS temperature slice file of $30{ }^{\circ} \mathrm{C}$ profiles with the most severe point assessment, FDS predicts the height and severity of smoke contamination in the balconies to within around $0.11 \mathrm{~m}$ of the experimental results except in one case where contamination is over-predicted by $0.68 \mathrm{~m}$. Generally, point recordings for temperature in FDS inside the balconies more closely match the experiments than those along the balcony edge. The overall temperature patterns from the simulations are similar to the experimental result, although the average predicted temperatures are noted to be slightly lower than the experimental values. Grid sensitivity analysis shows that refining the model grid can slightly increase the predicted temperatures; however, a significant difference has not been found in this study.

With the confidence built upon the simulation of the small-scale experiment and an interpretation methodology, the simulated heights of smoke contamination are superimposed onto the experimental results. The simulated and experimental results are each fitted with a power correlation that is found to be similar apart from the correlation of Tan et al. that under-predicts the smoke contamination where $w / d$ is 1.2 or less, whereas the correlation from the simulations performs better. The developed formula can be used in atrium designs with a heat release rate up to $5 \mathrm{MW}$, an atrium height up to $35 \mathrm{~m}$ and a channelled spill plume from an opening width of between 2 and $10 \mathrm{~m}$. Smoke flow up vertical surfaces such as upstands appears to have a significant effect on smoke contamination of upper level balconies. Hence, more research is needed, and a designer must take care to ensure that the boundary conditions are appropriate when carrying out any FDS modelling. 


\section{NOMENCLATURE}

$b \quad$ balcony breadth $(\mathrm{m})$

$c_{p} \quad$ heat capacity of air $\left(\mathrm{kJ} \mathrm{kg}^{-1} \mathrm{~K}^{-1}\right)$

$C_{d} \quad$ effective coefficient of discharge at opening

$d \quad$ depth of smoke layer at the spill edge (m)

$D^{*} \quad$ characteristic length for determining the grid size (m)

$g \quad$ acceleration due to gravity $\left(\mathrm{m} \mathrm{s}^{-2}\right)$

$H \quad$ height of smoke contamination (m)

$\dot{M}_{w} \quad$ mass flow rate of gases at the compartment opening $\left(\mathrm{kg} \mathrm{s}^{-1}\right)$

$\dot{M}_{p, 3 D_{w}} \quad$ mass flow rate of the spill plume $\left(\mathrm{kg} \mathrm{s}^{-1}\right)$

$n_{\text {spill }}^{*} \quad$ coefficient for determining grid size

$\dot{Q} \quad$ total heat release rate $(\mathrm{kW})$

$\dot{Q}_{c} \quad$ convective heat flow in the gas layer below the spill edge $(\mathrm{kW})$

$R \quad$ coefficient for determining grid size or correlation coefficient

$T_{\infty} \quad$ ambient temperature $(\mathrm{K})$

w width of compartment opening or width of line plume (m)

$z \quad$ height of rise of plume from spill edge (m)

$z_{\text {trans }} \quad$ transition height of spill plume (m)

$z^{*} \quad$ characteristic length of modelling (m)

\section{Greek symbol}

$\rho_{\infty} \quad$ air density at ambient temperature $\left(\mathrm{kg} \mathrm{m}^{-3}\right)$ 


\section{REFERENCES}

1. Cox G. Combustion Fundamentals of Fire. Academic Press: London, UK, 1995.

2. Morgan HP, Ghosh BK, Garrad G, Pamlitschka R, Smedt JCD, Schoonbaert LR. Design

Methodologies for Smoke and Heat Exhaust Ventilation. Building Research Establishment: Watford, UK, 1999.

3. NFPA 92B. Smoke management systems in malls, atria, and large spaces. National Fire Protection Association, USA, 2009.

4. Hansell GO. Heat and mass transfer process affecting smoke control in atrium buildings. $\mathrm{PhD}$ thesis, South Bank University, UK, 1993.

5. Law M. Measurement of balcony smoke flow. Fire Safety Journal 1995; 24:189-195.

6. Poreh M, Regev A, Marshall NR. Entrainment by adhered two-dimensional plumes. Fire Safety Journal 2008; 43:344-350.

7. Harrison R, Spearpoint M. The balcony spill plume: entrainment of air into a flow from a compartment opening to a higher projecting balcony. Fire Technology 2007; 43:301-317. 10.1007/s10694-007-0019-3.

8. Tan F, Harrison R, Spearpoint MJ. Physical scale modeling of smoke contamination in upper balconies by a channelled balcony spill plume in an atrium. Journal of Fire Sciences 2010; 28:313336. 10.1177/0734904109350151.

9. Tilley N, Merci B. Application of FDS to adhered spill plumes in atria. Fire Technology 2009; 45:179-188.

10. Quintiere JG, Grove BS. A unified analysis for fire plumes. Twenty-Seventh Symposium (International) on Combustion. The Combustion Institute, 1998, 2757-2766.

11. Harrison R, Spearpoint M. Characterisation of balcony spill plume entrainment using physical scale modelling. Fire Safety Science. Proceedings of the Ninth International Symposium. B. Karlsson, ed. Karlsruhe, Germany: International Association for Fire Safety Science, 2009, 727-738.

10.3801/IAFSS.FSS.9-727.

12. Chow WK. Numerical simulations on balcony spill plume. Fire and Materials 1999; 23:91-99.

13. Chow WK, Li J. Simulation on natural smoke filling in atrium with a balcony spill plume. Journal of Fire Sciences 2001; 19:258-277.

14. Kerber S, Milke JA. Using FDS to simulate smoke layer interface height in a simple atrium. Fire Technology 2007; 43:45-75. 10.1007/s10694-007-0007-7

15. McCartney C, Lougheed GD, Weckman EJ. CFD investigation of balcony spill plumes in atria. ASHRAE Transactions 2008; 114 (pt. 1):369-378.

16. Ho CL. Simulation of smoke contamination in upper balcony by a channelled balcony spill plume in an atrium. Fire Engineering Research Report, University of Canterbury, New Zealand, 2010.

17. Ji J, Fan CG, Zhong W, Shen XB, Sun JH. Experimental investigation on influence of different transverse fire locations on maximum smoke temperature under the tunnel ceiling. International Journal of Heat and Mass Transfer, 2012, 55:4817-4826.

18. Klote JH. State-of-the-art Atrium Smoke Control. HPAC Engineering: Cleveland, USA, 2008.

19. Drysdale D. An Introduction to Fire Dynamics (2ndedn ). John Wiley \& Sons Ltd.: England, 1998.

20. McGrattan K, McDermott R, Hostikka S, Floyd J. Fire Dynamics Simulator User's Guide, version 5. NIST special publication 1019-5, 2010.

21. Quintiere JG, Ma TG. Numerical simulation of axi-symmetric fire plumes: accuracy and limitations. Fire Safety Journal 2003; 38:467-492. 
22. Harrison R, Spearpoint M, Fleischmann C. Numerical modeling of balcony and adhered spill plume entrainment using FDS5. Journal of Applied Fire Science 2010; 17:337-366.

10.2190/AF.17.4.c.

23. Buchanan AH. Structural Design for Fire Safety. John Wiley \& Sons Ltd.: England, 2002.

24. Ji J, Gao ZH, Fan CG, Zhong W, Sun JH. Study of the effect of plug-holing and boundary layer separation on natural ventilation with vertical shaft in urban road tunnel fires. International Journal of Heat and Mass Transfer, 2012, http://dx.doi.org/10.1016/j.ijheatmasstransfer.2012.06.014 